Article

\title{
Spare Parts Inventory Management: A Literature Review
}

\author{
Shuai Zhang ${ }^{1}$, Kai Huang ${ }^{1, *}$ and Yufei Yuan ${ }^{2}$ (D) \\ 1 Area of Operations Management, DeGroote School of Business, McMaster University, \\ Hamilton, ON L8S4M4, Canada; zhans72@mcmaster.ca \\ 2 Area of Information System, DeGroote School of Business, McMaster University, \\ Hamilton, ON L8S4M4, Canada; yuanyuf@mcmaster.ca \\ * Correspondence: khuang@mcmaster.ca
}

Citation: Zhang, S.; Huang, K.; Yuan, Y. Spare Parts Inventory Management: A Literature Review. Sustainability 2021, 13, 2460. https://doi.org/10.3390/ su13052460

Academic Editor: Rajbir Bhatti

Received: 27 December 2020

Accepted: 20 February 2021

Published: 25 February 2021

Publisher's Note: MDPI stays neutral with regard to jurisdictional claims in published maps and institutional affiliations.

Copyright: (c) 2021 by the authors. Licensee MDPI, Basel, Switzerland. This article is an open access article distributed under the terms and conditions of the Creative Commons Attribution (CC BY) license (https:// creativecommons.org/licenses/by/ $4.0 /)$.

\begin{abstract}
Spare parts are held as inventory to support product maintenance in order to reduce downtime and extend the lifetime of products. Recently, spare parts inventory management has been attracting more attention due to the "right-to-repair" movement which requires that manufacturers provide sufficient spare parts throughout the life-cyle of their products to reduce waste so as to achieve sustainability. In this review, 148 papers regarding spare parts inventory management published from 2010 to 2020 are examined. The studies are classified based on two groups of perspectives. The first group includes the characteristics of spare parts, products, inventory systems, and supply chains, while the second group focuses on the characteristics of research methodologies and topics in the reviewed studies. The novelty of this literature review is three-fold. Firstly, we focus on analyzing the supply chain structure of different inventory networks for managing spare parts. Secondly, we classify the current literature based on analytics techniques, i.e., descriptive analytics, predictive analytics, and prescriptive analytics. Finally, the research gaps in this field are discussed from the perspective of reverse logistics, consumer durable goods, inventory network structure and policy, spare parts demand pattern modeling, and big data analytics.
\end{abstract}

Keywords: spare parts; inventory management; operations research; management science; supply chain sustainability; optimization

\section{Introduction}

Nowadays, manufacturers usually advocate for a culture of planned obsolescence. The idea of such a culture is to design their products to be short-lived and make products hard to repair, so that customers are encouraged to purchase more. However, this culture contributes to wasting more natural resources and energy, further escalating global warming. For example, the carbon emissions of producing the newest iPhone account for nearly 80 percent of the total emissions during its life-cycle [1]. To discourage this culture and achieve supply chain sustainability, a movement known as "right to repair" is starting to make progress in pushing for legislation that requires companies make their parts, tools, and information available to consumers and repair shops [2]. Under this circumstance, spare parts inventory management is attracting more attention from practitioners and academia. Spare parts are stock items used in maintenance activities to keep equipment or products in operating conditions [3]. Spare parts inventory management is critical because the cost of spare parts accounts for a large share of the products' life-cycle cost: the value of spare parts annually consumed by a piece of machinery, which might have a lifetime of around 30 years, amounts to nearly $2.5 \%$ of the original purchasing price [4]. The non-availability of spare parts may induce great financial losses for product owners. In some industries where the manufacturers provide after-sales services, good spare parts inventory management can improve customer satisfaction by reducing product downtime [5]. Furthermore, spare parts often have an obsolescence problem, which leads to spare parts being discarded at a quite low value. Overall, spare parts inventory 
management plays an important role in achieving the desired product availability at the minimum economic and environmental costs. However, the management of spare parts faces several difficulties. Firstly, the number and variety of spare parts are usually very large. Secondly, the intermittent demand patterns are common among spare parts, and are difficult to predict. Thirdly, the consumption of spare parts is related to the product usage, damage, and maintenance [4].

\subsection{Motivations and Objectives}

The goal of this review is to provide a quick guide to a variety of classification schemes to the spare parts inventory management literature and to present a big picture on spare parts supply chains to discuss the studies on spare parts inventory management. Over the last decade, a significant number of studies on spare parts inventory management have been published to provide managerial insights to practitioners, but to the best of our knowledge, there is no literature review that organizes the current literature from the perspectives of supply chain management and supply chain analytics. There have been seven literature reviews on this topic in the last thirty years. Ref [6] reviewed the studies on optimal maintenance and replacement models for multi-unit systems and classified them into five categories based on maintenance operations. In their review, spare parts inventory management was only a sub-topic. Ref [7] presented a review on the studies of repairable spare parts inventory management, and the reviewed studies were grouped based on network structure, solution methodology, and solution types. Ref [3] presented the first review which completely focused on the literature of spare parts inventory management, and the relationships between equipment maintenance and spare parts inventory were analyzed. Ref [8] gave a review on lateral transshipments within an inventory system. Ref [9] limited their literature review to models for non-repairable spare parts. Ref [10] focused on managing spare parts inventories of technical systems. The classification in their review was made based on the characteristics of the inventory network, including the network's service provider, number of echelon levels, and availability of lateral or emergency transshipment, etc. Ref [4] presented a framework for operational research (OR) in spare parts inventory management and analyzed the literature on four critical aspects of OR in spare parts inventory management, i.e., spare parts classification, demand forecasting, inventory optimization, and supply chain system simulation.

The main differences between our literature review and the aforementioned reviews are as follows. Firstly, we focus on analyzing the supply chain structure of different inventory networks for managing spare parts. Secondly, we classify the literature according to three analytics techniques, i.e., descriptive analytics, predictive analytics, and prescriptive analytics. Thirdly, we point out several new research gaps which combine spare parts inventory management with supply chain sustainability, big data analytics, and so on.

\subsection{Methodology}

In this review, the database used for searching publications was ABI/INFORM Collection, which is one of the most comprehensive business databases in the OR/MS field. The initial search was conducted by searching spare and inventory as keywords in the titles and abstracts in peer reviewed publications published between January 2010 and January 2020. After this initial search, 124 studies were identified. Then we used Google Scholar to search for studies citing them. In total, there were 148 studies in the review pool. After taking out the seven aforementioned reviews, 142 studies remained.

\section{Typology Based on Systematic Characteristics}

In this section, the reviewed papers are classified based on the characteristics of their studied products or spare parts and supply chain structures and inventory attributes for managing those products and spare parts. In the first subsection, five types of product and spare part characteristics including product system type, product life-cycle phase, spare part type, product system complexity, and performance measures are used to depict 
the studied product and spare parts in the literature. As for the perspective relating to spare parts supply chain characteristics, supply chain features such as network ownership, number of echelons, lead time, lateral transshipments and emergency shipments, and after-sale services are summarized and analyzed in Section 2.2. In the final subsection, inventory management characteristics including inventory policy, number of inventory items, and inventory supply source are introduced to classify the studies.

\subsection{Product and Spare Parts Characteristics}

Five product and spare part characteristics are summarized in Table 1.

Table 1. Number of studies in different product and spare part characteristics.

\begin{tabular}{|c|c|c|c|c|c|c|c|c|c|}
\hline \multicolumn{2}{|l|}{ Product Types } & \multicolumn{2}{|c|}{ Product Life-Cycle Phases } & \multicolumn{2}{|l|}{ Spare Part Types } & \multicolumn{2}{|c|}{ Product System Complexity } & \multicolumn{2}{|c|}{ Performance Measures } \\
\hline Capital goods & 109 & Initial phase & 2 & Repairable parts & 41 & Single-unit products & 60 & LCC measure & 8 \\
\hline Consumer durable goods & 18 & Maturity phase & 80 & Non-repairable parts & 83 & Multi-unit products & 76 & TCO measure & 2 \\
\hline Non-specific goods & 15 & End-of-life phase & 9 & Both & 8 & & & SCOR measure & 114 \\
\hline & & Whole life-cycle & 11 & & & & & Other measures & 4 \\
\hline
\end{tabular}

\subsubsection{Product Types}

Spare parts are stocked and used for keeping equipment in operating conditions. The management of spare parts is a critical element in the after-sales service supply chain. Capital goods and consumer durable goods are two important product types which have a long lifetime and require after-sales services [11]. The former are high-value tangible assets used by a company as an input for producing other goods or services, and are also referred to as capital assets. The latter refer to the products purchased by individual customers and are not used for producing another good or service. Examples of consumer durable goods include automobiles, household appliances, and consumer electronics. Normally, capital goods are essential to the operation processes of the owner company. Therefore, a high availability of capital goods needs to be ensured [12]. Examples of capital goods include computer networks, medical and defense systems, and aircrafts.

There are several differences between these two categories. Capital goods directly involve producing goods or providing services, while consumer durable goods do not. Second, they are supported by distinct after-sales services. Service contracts are provided by the OEMor a third party maintenance company for capital goods. Warranties are usually provided for consumer durable goods. Third, these two goods have different spare parts demand patterns. Consumer durable goods are purchased by a large number of individuals, leading to significant variations in spare parts demand because product usage varies among customers. For capital goods, owners usually purchase a fleet of identical products in use and these products normally have the same usage levels and work under the same environment. On the other hand, for consumer durable goods, the law of large numbers holds for spare parts demand because the product's installed base is sufficiently large, meaning that the OEM is able to take advantage of this property to make inventory decisions. In contrast, the installed base of capital goods is usually not large enough, especially for the network managed by the equipment owner, who is more likely to be faced with irregular spare parts demand patterns.

According to Table 1, the studies on spare parts of capital goods prevail in this research area: 109 out of 142 studies focus on the spare parts of capital goods, and only 18 studies consider the spare parts of consumer durable goods. Meanwhile, we cannot identify the product types in 15 papers. This result indicates a notable research gap in managing spare parts of consumer durable goods, and such a gap will be discussed in part b of Section 4.1.2.

\subsubsection{Product Life-Cycle Phases}

The product life-cycle consists of three phases, including the initial phase, maturity phase, and end-of-life (EOL) phase [10]. The demands for products and those for spare 
parts behave differently throughout the life-cycle. The initial phase begins when a new product is launched. The product demand increases sharply during the initial phase and the number of products on the market surges as well. In contrast, the product failure due to deterioration is very low, implying that the spare parts demand is not significant during this phase. After the initial phase, the maturity phase starts when the number of products on the market becomes stable. Such stability is caused not only by the declining product demand, but also by the increasing product failures, which also incur increasing spare parts demands. The EOL phase usually starts when the manufacturing of products and spare parts stops and when the last warranty or service contract period expires [13]. During this phase, product sales cease and on-market product quantity starts to decrease, while the supply of spare parts stops. However, products on the market still need to retain functionality when they fail, requiring spare parts be procured and then stocked at the beginning of this phase. Figure 1 illustrates the life-cycle phases. Importantly, spare parts demand follows product demand but with a time lag, called the "life-cycle mismatch" phenomenon [14]. Such mismatch indicates that spare parts demand is correlated with on-market product quantity [15].

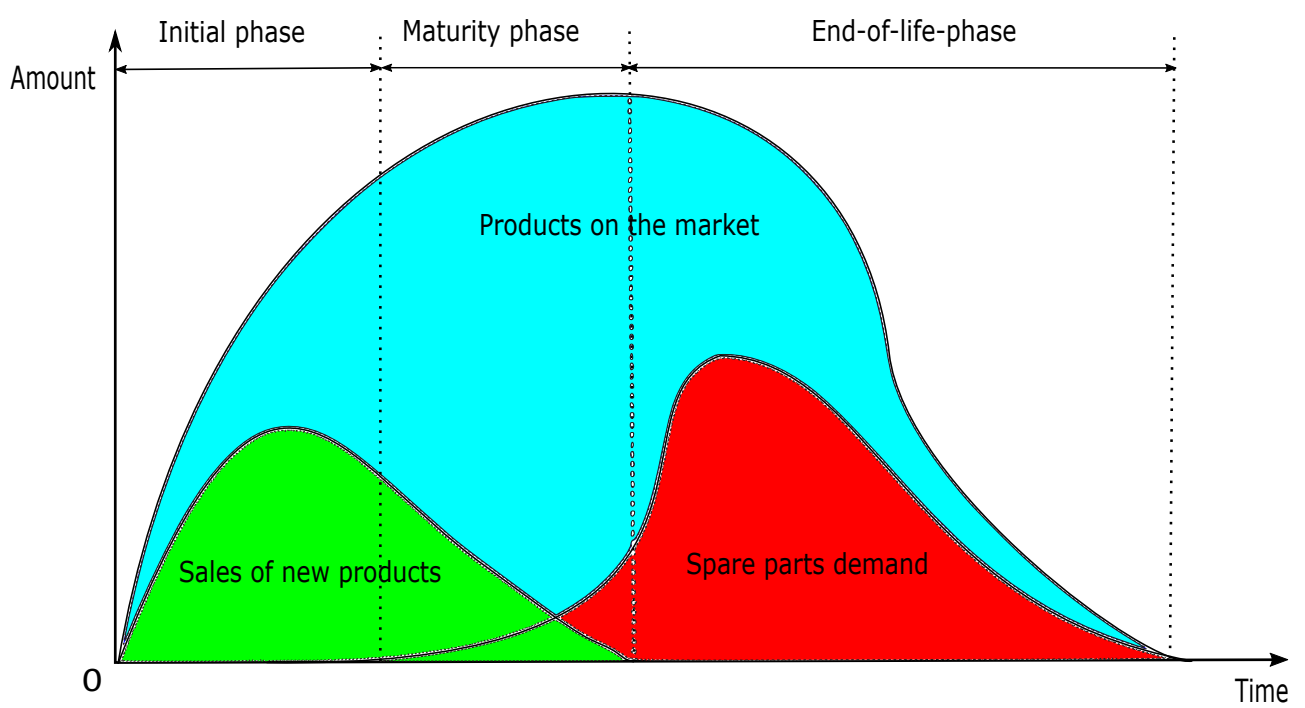

Figure 1. New products sales, spare parts demand, and products on market in the product life-cycle (adapted form [15]).

As shown in the second column of Table 1, most studies in the spare parts inventory management literature focus on the inventory problems arising during the maturity phase when on-market product quantity is stable. There are nine studies focusing on the final order problem or last-time-buy problem occurring in the EOL phase. Additionally, four studies focus their efforts on spare parts inventory management over the entire life-cycle. The other 40 studies cannot be classified because they do not indicate the life-cycle phases they focus on. It is clear that the extant studies lack the life-cycle planning perspective, and we will present the discussion on this research gap in part b of Section 4.1.2.

\subsubsection{Spare Part Types}

The spare parts in the reviewed studies mainly include two types, i.e., repairable parts and non-repairable parts. Repairable parts are items which are replaced by new ones and then sent to repair when failure occurs [12]. After being repaired, the parts are restocked as ready-for-use units (RFUs), which are used to replace faulty ones in the future. Non-repairable parts, also referred to as consumables, are items which cannot be repaired after replacement and are usually discarded. The inventory management of repairable parts is more complex than that of consumables. For repairable parts, supply sources include not only suppliers, but also repair workshops, whose operations are affected by repair capacity, repair time, etc. 
As shown in the third column of Table 1, there are 41 studies focusing on repairable parts, while there are three studies considering both repairable and non-repairable parts. More than half of the studies focus on non-repairable parts. Ten studies do not specify the types of spare parts. However, such emphasis on non-repairable parts is not able to satisfy the urgent need for managing repairable parts among practitioners, especially when the concept of supply chain sustainability has prevailed in industry recently. Based on such an observation, the research gaps regarding reverse logistics of spare parts will be presented in Section 4.1.1.

\subsubsection{Product System Complexity}

In terms of system complexity, the product systems can have a single critical part (single-unit system) or multiple critical parts (multi-unit system). The fourth column of Table 1 indicates the studies based on system complexity. From the table, we can see that the studies on both kinds of product system are quite abundant in the literature. However, one interesting observation is that most multi-unit system studies assume the independence of spare parts failures. Only two studies [16,17], adopt the dependent failures assumption. In the real world, independent failure assumption is often invalid, though it simplifies the analysis. In this case, we emphasize that more future studies on multi-unit system should take the dependent failure assumption into consideration.

\subsubsection{Performance Measures}

In the literature, various performance measures are used to evaluate the outcomes brought by different inventory policies, maintenance schedules, etc. In the following, three different measures are introduced. These performance measures are adopted by the inventory network owners to manage the spare parts inventory for different products. Typically, if OEMs manage the spare parts inventory network to provide after-sales services, they are interested in the life-cycle cost of the manufactured product, because it is an important factor to consider when designing products and deciding after-sales services strategies. For the product users who build up their own spare parts inventory networks for maintaining the purchased products, the total cost of ownership is one of their main concerns, because it helps them understand the true cost of buying the products from a particular OEM. In addition, both OEM and product users may focus on the supply chain performance metrics to meet their specified operation requirements for the spare parts supply chain. In the following context, three different measures including life-cycle cost, total cost of ownership, and supply chain performance metrics, are introduced and the reviewed literature is classified based on these measures.

\section{a. Life-cycle cost}

Life-cycle cost (LCC) is referred to as the summation of all cost components for manufacturers, users, and society during the product lifetime. The breakdown structure is shown in Table 2, adapted from [18].

The difference between this table and that of [18] is that OEM may also have disposal or recycling costs if reverse logistics (RL) are implemented. Detailed discussions on the relationship between RL and spare parts inventory management are given in Section 4.2. More importantly, when conducting LCC analysis, the cost categories considered are different for OEM, users, and society, because they are only interested in the cost components that they can control. For example, ref [19] studied a problem in which an OEM provides the performance-based contract $(\mathrm{PBC})$ to the customer who purchased a set of equipment. The life-cycle cost considered in their study includes the design costs, production costs, and usage costs, and is affected by the product's reliability level and spare parts inventory level.

\section{b. Total cost of ownership}

Total cost of ownership (TCO) is a concept which helps customers to understand the true cost of buying a particular good or service from a supplier [20]. In addition to prod- 
uct price, TCO normally contains the costs incurred by product maintenance, downtime, disposal, and other activities that occur during the usage of the product. Note that the maintenance-related cost may account for a large portion (70-80\%) of the TCO for complicated technical systems [19]. Hence, spare parts inventory management is important due to its critical role in maintenance operations.

It should be highlighted that the maintenance-related cost may account for a very large portion (70-80\%) of the TCO for some complicated technical products, such as military, medical, and power generation equipment. Therefore, spare parts inventory management is important due to its critical role in maintenance operations. The studies that adopt the $\mathrm{TCO}$ as the performance measure for evaluating the spare parts inventory system generally seek to find the optimal inventory policy, such that the TCO is minimized.

c. Supply chain performance metrics

In the literature, the Supply Chain Operation Reference (SCOR) model is widely used to measure supply chain performance. This model measures supply chain performance from four perspectives, i.e., lead time metrics, cost metrics, service/quality metrics, and assets metrics [21], illustrated in Table 3.

Table 2. Life-cycle stages and costs.

\begin{tabular}{llll}
\hline & OEM Cost & Users Cost & Society Cost \\
\hline \multirow{2}{*}{ Design } & Product development & & \\
& Market Recognition & & \\
\hline \multirow{2}{*}{ Production } & Materials & & Wastes \\
& Labors & & Pollution \\
& Facilities & & Health damages \\
& Energy & & \\
\hline \multirow{2}{*}{ Usage } & Inventory & Inventory & Packaging \\
& Transportation & Transportation & Wastes \\
& Wastes & Energy & Pollution \\
& Breakage & Materials & Health damages \\
Disposal & After-sales services & Maintenance & \\
or & Disposal & Disposal & Wastes \\
recycling & Recycling & Recycling & Disposal \\
& Remanufacturing & & Pollution \\
& & & Health damages \\
\hline
\end{tabular}

Table 3. Different kinds of supply chain performance metrics.

\begin{tabular}{ll}
\hline Metrics & Example \\
\hline Lead time metrics & $\begin{array}{l}\text { Spare part replenishment lead time, repair lead time for re- } \\
\text { pair operation, etc. }\end{array}$ \\
\hline Cost metrics & $\begin{array}{l}\text { Inventory holding cost, repair cost for repairable spare parts, } \\
\text { shipment cost, etc. }\end{array}$ \\
\hline Service/quality metrics & $\begin{array}{l}\text { Product's availability level, inventory system service } \\
\text { level, etc. }\end{array}$ \\
\hline Assets metrics & Spare parts inventory level, repair center capacity, etc. \\
\hline
\end{tabular}

The number of reviewed studies which use different performance measures are listed in the final column of Table 1. It is worth mentioning that more than one performance measure can be used to evaluate the system performance. For example, an OEM who provides performance-based contracts to the customer has to not only consider the cost metrics of the maintenance and inventory system, but also ensure that the requested service 
metrics in the contract be satisfied (e.g., the required product availability level). In this case, one can use the total cost induced by managing spare parts as an objective, while the agreed service level acts as the constraints in optimization models. Consequently, we consider the number of usages of different performance measures in the reviewed literature.

The last column of Table 1 clearly shows that supply chain performance metrics are dominantly used in the literature. In contrast, eight studies adopt the LCC measure and two studies use the TCO measure, respectively. There are four studies using other measures such as company profits of selling products and providing warranty services [11,22], profits of using spare parts inventory pooling among different companies [23], and warranty cost [24]. This observation indicates that research on spare parts inventory management should consider advanced warranty types.

\subsection{Perspective of Spare Parts Inventory Management Characteristics}

In this subsection, the reviewed literature is classified based on the characteristics of spare parts inventory management, including inventory policy, number of inventory units, and inventory supply source.

\subsubsection{Inventory Policy}

During a product's life-cycle, various policies are implemented to manage the spare parts inventory. Continuous review and periodic review policies are commonly used in the initial and maturity phases, while final order policies are widely used in the EOL phase.

\section{a. Continuous review policy}

Under a continuous review policy, the spare parts inventory level is monitored in a continuous manner. We can identify two types of continuous review policy, including $(s, S)$ policy and $(q, r)$ policy. In the $(s, S)$ policy, a new order is placed to make the inventory level reach the order-up-to level $(S)$ once the level falls below reorder point $(s)$. The ordered quantity is equal to the difference between $S$ and inventory level at the ordering time. The $(S-1, S)$ policy, referred to as one-for-one replenishment policy or base stock policy, is a special case of $(s, S)$ and is widely used for repairable spare parts because the onefor-one replenishment mode can mimic the repair process. For example, when a product is under repair, inducing one unit demand for a repairable spare part, a new spare part is used to replace the faulty one, which is sent to repair and will return as one unit of inventory after repair. Unlike the $(s, S)$ policy, whose order size is uncertain, the $(q, r)$ policy has a fixed order size $(q)$ and the order is placed when inventory level is no higher than the reorder point $(r)$.

\section{b. Periodic review policy}

Under a periodic review policy, the spare parts inventory level is monitored in a cyclic or periodic manner. The most widely used periodic review policy is $(R, S)$ policy, in which orders are placed at the start of every fixed ordering cycle $(R)$ to ensure that the inventory level reaches the order-up-to level $(S)$. The length of ordering cycle is usually predetermined by decision makers. It is notable that the implementation of continuous review or periodic review policy is mainly decided by the decision makers based on how the spare parts inventory is managed. In addition, it is possible to adopt both inventory policies in an particular inventory network. For example, in some studies, different inventory policies are used in different echelons of a multi-echelon inventory network [25].

\section{c. Final order policy}

When the production of spare parts is discontinued, a final order is placed to satisfy the demand during the EOL phase [13]. In the literature, this is called the EOL inventory problem, end of production problem (EOP), or final buy problem (FBP). If too many spare parts are ordered, the inventory owner would take large obsolescence and disposal risks and pay for a high inventory holding cost in the EOL phase. On the contrary, if the final ordered quantity was not enough to cover the spare parts demand during the final period, 
the OEM or maintenance provider would not fulfill the service contracts or warranty obligations, and thus be faced with fiscal penalties or damage to customer satisfaction or brand image.

Table 4 summarizes the studies on different inventory policies. Note that a study may involve different policies and is included in more than one category. From the table, we can see that the implementation of various inventory policies depends on the type and life-cycle phase of the studied products or spare parts. This is the reason that each mentioned policy is studied in a fair amount of studies.

Table 4. The number of studies using different inventory policies.

\begin{tabular}{ccccc}
\hline \multicolumn{4}{c}{ Initial and Maturity Phases } & EOL Phase \\
\hline \multicolumn{2}{c}{ Continuous review policy } & Periodic review policy & \multirow{2}{*}{ Final order policy } \\
\hline$(s, S)$ & $(S-1, S)$ & $(q, r)$ & $(R, S)$ & \\
\hline 12 & 51 & 12 & 36 & 7 \\
\hline
\end{tabular}

\subsubsection{Number of Inventory Items}

Based on the inventory item numbers, the literature can be categorized into two groups: the studies with a single-item inventory and the studies with a multi-item inventory. This classification is closely related to the definition of the service level of inventory system, which includes the item approach and system approach. In the former, each inventory item has its own target service level and ordering decisions should be made for each item independently. In contrast, in the latter, a target service level is defined for the demand weighted average of performance measures over all items [25]. The studies on multi-item spare parts inventory systems are prevalent, with 85 studies focusing on this characteristic, whereas 44 studies are on single-item inventory system. In addition, there are 13 studies not classified because they do not cover this issue.

\subsubsection{Inventory Supply Sources}

Both consumable and repairable spare parts are normally procured from external suppliers or manufactured by OEM's. However, it is possible that repairable spare parts are supplied from repair shops by fixed faulty ones. The identification of supply source is important because different supply modes represent various emergency levels of orders. For example, when the inventory is depleted and orders cannot be backlogged, ordering new spare parts from external suppliers is more preferable if the lead time is short because waiting to repair a faulty part possibly costs more (e.g., penalties on long customer waiting time beyond the agreed level in the service contracts). From Table 5, it can be concluded that the inventory supply sources in most studies are suppliers and repair shops. There are only four studies with other supply modes, such as remanufacturing [22], additive manufacturing [26], and cannibalization [27,28]. These results reveal that the current studies still focus on the typical inventory sources such as procurement from external suppliers and supplies from repair shops. In fact, as the concept of supply chain sustainability becomes more important, more studies should consider the new inventory sources including remanufacturing, additive manufacturing, etc.

Table 5. Number of studies with different supply sources.

\begin{tabular}{cccc}
\hline Suppliers & OEM Production & Repair Shop & Others \\
\hline 52 & 5 & 73 & 4 \\
\hline
\end{tabular}

\subsection{Perspective of Spare Parts Supply Chain Characteristics}

The spare parts supply chain refers to the network of firms and facilities transforming raw materials into spare parts and distributing these spare parts. The supply chain charac- 
teristics reveal stakeholders, structure, operations mode, and flow paths of the spare parts supply chain. The obtained results are shown in Table 6.

Table 6. Number of studies on different spare parts supply chain characteristics.

\begin{tabular}{|c|c|c|c|c|c|c|c|c|c|}
\hline \multicolumn{2}{|l|}{ Network Ownership } & \multicolumn{2}{|c|}{ Number of Echelons } & \multicolumn{2}{|l|}{ Lead Time } & \multicolumn{2}{|c|}{$\begin{array}{l}\text { Lateral Transshipments and } \\
\text { Emergency Shipments }\end{array}$} & \multicolumn{2}{|l|}{ Maintenance Strategies } \\
\hline User network & 49 & Single echelon & 90 & Zero lead time & 21 & Lateral trans-shipments & 5 & Preventive maintenance & 31 \\
\hline OEM & 55 & Multi echelon & 32 & Deterministic lea & 59 & Emergency shipments & 17 & haintenance & 86 \\
\hline Third party network & 28 & & & Stochastic lead time & 38 & Both & 2 & Both & 20 \\
\hline
\end{tabular}

\subsubsection{Network Ownership}

Based on network ownership, a spare parts supply chain can be identified as an OEM network, a user network, and a third-party network [10]. A user network is a traditional network for maintaining the products in use, where users take over maintenance activities to avoid downtime. As the product structure and maintenance complexity have increased, OEM networks have started to prevail in many industries such as high-tech industries, because the OEM generally possesses more knowledge and techniques, and thus can handle the complexity of product system more easily than users. In addition, the prevalence of lean management programs is another driver of this trend. The philosophy of lean management requires that users have smaller buffers for disturbances and also high system availability. In this context, rather than reserving the teams and resources to maintain the product systems in use, users prefer outsourcing the maintenance to the OEM or a third-party company.

In an OEM network, the OEM establishes facilities and resources to provide after-sales services to users via service contracts or warranties. Nowadays, OEMs are increasingly willing to provide after-sale services due to the following reasons. Firstly, providing such services induces a competitive advantage over other OEMs, since customers increasingly require high-quality after-sales services; secondly, the OEM can earn profits by selling such services, which can be higher than selling products.

In some cases, a third-party firm takes the role of the OEM, called a third-party network. In other words, a third-party network is similar to an OEM network. For example, both the OEM and third-party company own and manage the facilities and resources to support the after-sales services. The major difference is after-sales services in a thirdparty network usually are provided to a much bigger user group who use products from different OEMs. In the first column of Table 6, the number of studies adopting networks with various ownership is summarized: there are 49 studies on user networks, 55 studies on OEM networks, and 28 studies on third-party networks. In addition, we cannot identify the network types in 10 papers, because no related information is provided. This result indicates that all these three types of spare parts inventory network are studied sufficiently in the reviewed literature.

\subsubsection{Number of Echelons}

The number of echelons is one of the most important characteristics in the inventory management literature, because it decides the structure of the inventory system. A singleechelon inventory system contains local stock points in different regions, where each local stock point is responsible for serving the demand in the region and no interaction exists between any two local stock points. A multi-echelon inventory system has more than one echelon. For example, national and regional stock points are utilized in this system. More importantly, replenishment decisions at each stock point may depend on the information of other stock points. The second column in Table 6 shows that a majority of the reviewed studies focus on single-echelon inventory systems, indicating a research gap in multi-echelon spare parts inventory systems. This research gap will be discussed in Section 4.1.3. 


\subsubsection{Lead Time}

Lead time is another important supply chain feature, usually defined as the period that begins with an order placement and ends with the receipt of that order. Different inventory policies lead to different lead times. For example, when emergency replenishment is allowed, an emergency order often leads to a shorter lead time but greater cost. In the literature, the concept of lead time varies among different spare part types. For nonrepairable spare parts, the lead time mainly include transportation time and repair time. As shown in the third column in Table 6, 21 studies do not consider lead times, while 97 studies do, among which 59 studies consider deterministic lead times and 38 studies consider stochastic ones. This reveals that current studies have accommodated to the real life scenarios which do have a lead time when placing an order. In addition, it is notable that more and more studies are focusing on handling the uncertainty in lead time brought by supply chain disruptions.

\subsubsection{Lateral Transshipments and Emergency Shipments}

Lateral transshipments and emergency shipments are widely used to improve inventory system performance in practice. The reviewed literature is classified based on whether the lateral transshipments or emergency shipments are used.

\section{a. Lateral transshipments}

Lateral transshipments are defined as stock movements between different stock points within the same echelon in an inventory system [10]. In some studies, inventory pooling and lateral transshipments are treated as interchangeable strategies [29]. Based on the timing when transshipment decisions are made, lateral transshipments can be categorized as proactive transshipments and reactive transshipments [8]. In the former, all transshipments are scheduled in advance and all stock points are redistributed simultaneously, while the latter refers to stock movements from one stock point with sufficient on-hand stock to another stock point with stock-out situation at any time. Another way to classify the literature regarding lateral transshipments is based on the extent to which the stock at one point is available to be used in transshipments. If all of the inventory at one stock point can be used, such transshipment is called complete pooling. In contrast, if only a portion of inventory can be transshipped and the rest of the inventory is reserved for covering future local demands, such transshipment is called partial pooling. However, we find that all the studies involving lateral transshipments use reactive transshipments with complete pooling.

\section{b. Emergency shipments}

Emergency shipments are widely used when on-hand spare parts stocks are insufficient to support timely maintenance activities. Unlike lateral transshipments, emergency transshipments involve stock movements between different echelons, i.e., the stock-out point and the inventory supply source. As shown in the fourth column of Table 6, there are only five studies considering lateral transshipments, 17 studies considering emergency shipments, and 2 studies considering both. The remaining 118 studies ignore or are irrelevant to this issue. This shows the lateral transshipments and emergency shipments represent a large gap in the spare parts inventory management literature, which will be illustrated in Section 4.1.3.

\subsubsection{After-Sales Services and Maintenance Strategies}

The after-sales service of product is highly relevant to the spare parts inventory management. Such services are regulated by the agreed contracts between product owners and maintenance providers, and are realized by different maintenance strategies. In the following, two different types of after-sales service, warranty and service contracts, are discussed and several maintenance strategies will be illustrated. 


\section{a. After-sales contracts}

Basically, there are two types of contracts, i.e., warranty and service contracts. As discussed earlier, the after-sales services of consumer durable goods are provided through warranty contracts, which request OEM to fix or replace faulty products for customers under some conditions. Warranty contracts are important strategic profiles in modern manufacturers because they can improve company image, generate business and profits, and foster brand [30]. On the other hand, after-sales services of capital goods are often provided through service contracts which includes material-based contracts (MBC) and performancebased contracts (PBC) [31]. Under MBC, each time a service task is completed, the OEM is compensated for the service cost, while under PBC, the OEM is compensated based on system performance. Compared to MBC, $\mathrm{PBC}$ has advantages in motivating OEMs to improve product quality and reliability during the design and manufacturing phases.

b. Maintenance strategies

Maintenance strategies determine the timing when products are maintained or parts are replaced, which is classified as preventive maintenance and corrective maintenance. Preventive maintenance intends to maintain products or replace parts before failure occurs to avoid product breakdowns, which assumes that the product state is known with certainty [6]. Preventive maintenance is scheduled in each planning period and induces planned demand for spare parts. However, preventive maintenance cannot eliminate part failures because parts might fail before replacements or maintenance. In addition, some types of spare parts, such as electronic parts, do not wear, meaning that the states of parts cannot be used to decide the maintenance schedule. In these cases, corrective maintenance strategies are used when part failures occur, which would incur unplanned demand for spare parts. The last column of Table 6 shows the number of studies on preventive and corrective maintenance, illustrating that both maintenance strategies are fairly extensively studied in the reviewed literature.

\section{Typology Based on Research Methodologies and Topics}

In Section 2.2, the reviewed literature is categorized according to the physical characteristics of the studied products, spare parts, and supply chain networks. These characteristics can be used to help readers to understand the backgrounds and contents of the studies on spare parts inventory management problems. However, to get a big picture of current research status, identify research gaps, and find potential study topics, the reviewed studies need to be classified based on research methodologies and topics. In this section, another typology based on research methodologies and topics in the reviewed papers is introduced and corresponding analysis is carried out. In the following sections, the reviewed studies are categorized based on the supply chain analytics which they use and the research topics which they focus on.

\subsection{Perspective of Supply Chain Analytics}

A spare parts supply chain refers to the network of firms and facilities involved in transforming raw materials into spare parts and distributing spare parts to customers. In this subsection, we use the concept of supply chain analytics to identify different research methodologies. Supply chain analytics can be divided into three different types, including descriptive, predictive, and prescriptive analytics. It is worth mentioning that one study may use multiple analytics techniques.

\subsubsection{Descriptive Analytics}

Descriptive analytics answer the question of what is happening by utilizing and deriving the information from significant amount of data [32]. Spare parts inventory management studies adopting descriptive analytics mainly focus on particular cases, conduct simulations, and perform performance analysis based on the collected historical data. The research issues are typically related to spare parts supply chain network structure 
design, spare parts classification, and new technology adoption for spare parts inventory management in a particular industry.

Our review shows that 49 studies have real-life cases relevant to spare parts inventory management problems. In these studies, the data were collected from the companies or organizations. There are 19 papers using simulation models to mimic the real-world spare parts inventory management processes. The purpose of using simulation models as a descriptive method is to reveal the value of implementing certain policies when managing a spare parts inventory. Using such simulation experiments is preferable because the cost of testing policies in real-life management operations could be high. Performance analysis is used in seven papers for testing or comparing different spare parts demand classification or forecasting methods.

\subsubsection{Predictive Analytics}

Predictive analytics answer the question of what will be happening by utilizing collected data in prediction techniques. The reviewed studies adopting predictive analytics normally address the issues of how to identify different spare parts demand patterns and how to correctly forecast the demand.

Spare parts demand is induced by the failures and replacements of parts in use during a product's life-cycle, and is often intermittent and lumpy [33], causing difficulties in demand forecasting. Spare part demand is often modeled by stochastic processes (SP). A stationary stochastic process (SSP) assumes that the demand possesses identical probability distributions in different time periods, which holds when the product installed base is large and constant over the planning horizon. The most widely used SSP is the Poisson process. On the contrary, a non-stationary stochastic process (NSSP) assumes that demand possesses different probability distributions across periods, which holds when the number of target products changes over the planning horizon. One typical NSSP is the non-homogeneous Poisson process. The selection between SSP and NSSP is affected by the product lifecycle phase. If one study targets only the products in the maturity phase, SSP is preferred because the number of products in use remains at a stable level, leading to a steady demand rate. However, the demands are not stable either at the initial phase or the EOL phase, where NSSP is preferred. Another popular approach for depicting demand patterns is to assume that demand follows a certain probability distributions. The assumed probability distribution in each planning period is uniquely determined by the information retrieved from the collected data and can be either similar or dissimilar. An advantage of this approach is that almost all types of demand pattern can be modeled based on historical observations. However, general probability distributions may bring more complexities into optimization problems.

Only a few studies assume deterministic spare part demands but put more effort into determining the optimal inventory policy. However, such deterministic models could not capture the stochastic nature of part failures. We summarize the studies using different demand patterns in Table 7. It is clear that a majority of the reviewed studies adopt SSP. The reason for this is that the spare parts inventory management literature is developed from and is heavily impacted by the equipment maintenance literature, in which SSP are widely accepted as a basic assumption. In addition, 20 studies assume general probability distributions. There are 24 studies which cannot be identified based on how demand patterns are modeled.

Table 7. Number of studies with different demand patterns.

\begin{tabular}{cccc}
\hline \multicolumn{3}{c}{ Stochastic } & \\
\cline { 1 - 3 } SSP & NSSP & General Distribution & \\
\cline { 1 - 3 } 74 & 10 & 20 & 4 \\
\hline
\end{tabular}


When there are multiple spare parts, multiple demand patterns usually exist. The literature can also be classified based on a single demand pattern and multiple demand patterns, including 42 and 66 studies, respectively. The former usually considers one type of spare part (could be multiple identical spare parts), while the latter considers multiple non-identical spare parts belonging to different types. More importantly, for the complex systems with multiple parts, one spare part's demand may be affected by the demand for other spare parts. However, most of the studies with multiple demand patterns assume that spare part demand patterns are independent, while only two papers [16,17] consider the dependency among different spare parts demand patterns.

\subsubsection{Prescriptive Analytics}

Prescriptive analytics answer the question of what should be happening. Specifically, prescriptive analytics utilize optimization models to provide recommendations to decision makers. In our review, 86 studies using prescriptive analytics are examined. To provide readers with a clear and direct view on the optimization models in the studies with prescriptive analytics, We further divide the studies into three aspects, i.e., model settings, optimization model types, and solution methods, shown in Table 8.

\section{a. Model settings}

Based on the types of model setting, the mentioned 86 papers can be classified into two groups, one with a stochastic setting and the other with a deterministic setting. If a model assumes spare part demand is stochastically distributed, we classify it as using a stochastic model setting. Instead, if the demand is assumed to be deterministic, we classify it as using a deterministic model setting. As shown in the first column of Table 8, the studies adopting stochastic settings dominate: 81 out of 86 studies use stochastic settings, while only 5 studies use deterministic settings, indicating that stochastic settings are widely accepted in this field.

b. Optimization model types

Note that a model with a stochastic setting does not necessarily lead to a stochastic optimization problem. For example, ref [34] considered a repairable spare parts inventory problem with a stochastic setting, i.e., the demand for each part is a Markov-modulated Poisson process, but the problem is formulated as a non-linear integer programming optimization problem. In the third column of Table 8, we classify the studies based on optimization model types. Stochastic optimization models include stochastic dynamic programming (Markov decision process) models, stochastic programming models, and robust optimization models. On the other hand, deterministic optimization models consist of linear programming models, non-liner programming models, and mixed integer linear/non-linear programming models. Table 8 shows that the studies using deterministic optimization models account for a majority. There are 22 studies using stochastic optimization models. Among them, very few studies use stochastic programming or robust optimization techniques. The diversity in modeling techniques can facilitate the development of this research area and bring more new innovative topics. Therefore, we call on more studies to propose various stochastic optimization models. More discussion on this future research direction will be presented in Section 4.1.4.

\section{c. Solution methods}

The 86 studies propose various methods to solve the problems, including exact methods, approximation methods, heuristic methods, and simulation methods. Exact methods are able to find optimal solutions or bounds on optimal solutions to optimization problems. Large-scale optimization methods such as branch-and-bound, Lagrangian relaxation, and Benders decomposition are also considered as exact methods. The basic idea of approximation methods is that when the objective function in the studied problem is hard to evaluate, that function can be sampled at a few points to create a fit, and optimization is then performed on this fit. Heuristic methods are used when the problems have high 
computational complexity. They are simple and easy to implement but optimal solutions cannot be guaranteed. Simulation methods are defined as using simulation experiments to find the best input variable values among all possibilities without explicitly evaluating each possibility [35]. The 86 studies adopting different solution methods are summarized in the last column of Table 8. It should be noted that in some studies, multiple solution methods are proposed. In this case, the papers with multiple solution methods are included in more than one category. From the results, we can see that exact and heuristic methods are most widely used in the reviewed literature. This indicates that most complicated problems are solved by heuristics without any guarantees on the solution's optimality. Hence, we call on more research with approximation methods for solving problems in this area to provide high-quality solutions in reasonable solution time.

Table 8. Number of studies on different prescriptive analytics characteristics.

\begin{tabular}{lllll}
\hline \multicolumn{1}{c}{ Model Settings } & \multicolumn{1}{c}{ Model Types } & & \multicolumn{1}{c}{ Solution Methods } \\
\hline Stochastic setting & 81 & Stochastic dynamic programming & 19 & Exact method \\
Deterministic setting & 5 & Stochastic programming & 2 & Approximation method \\
& & Robust optimizations & 1 & Heuristic method \\
& & Deterministic optimization model & 64 & Simulation method \\
\hline
\end{tabular}

\subsection{Perspective of Existing Research Topics}

In this section, the reviewed studies are further classified based on four research topics, i.e., joint maintenance and inventory optimization, the spare parts inventory management problem, supply chain network design or performance evaluation, and spare parts classification and demand forecasting, including 52, 33, 24, and 28 studies, respectively. There are 12 studies that do not fall into these topics. Among them, seven are review papers, and the rest investigate scattered research problems.

\subsubsection{Joint Maintenance and Inventory Optimization}

Joint maintenance and inventory optimization is the most studied research topic. Spare parts inventories are provided to support maintenance operations. Due to the high interaction between maintenance and spare parts inventory management, the decision-maker should consider them simultaneously [9]. On this topic, efforts are made to investigate the performance of different combinations of inventory policies and maintenance strategies. Note that several studies consider the service contracts design for after-sales services providers $[23,24,31,36]$.

\subsubsection{Spare Parts Inventory Management Problem}

Unlike final products whose inventory is provided as a source for delivery to customers, spare parts are kept to keep products in operating conditions. The demand pattern of spare parts is quite different from that of final products. Furthermore, spare parts have large obsolescence risks when the supported products quit the market. Due to these differences, the optimal policies for final products are usually sub-optimal for spare parts inventories [3]. In addition, the repairable spare parts inventory problem is more complicated than that of non-repairable spare parts, because repair operations and resources need to be taken into consideration.

\subsubsection{Supply Chain Network Design or Performance Evaluation}

The studies focusing on this topic mainly design new systems implementing new operations or technologies to manage spare parts inventories, and evaluate the resulting performance. For example, more and more spare parts come from reusing or remanufacturing parts in used products. In this case, some studies try to incorporate reverse logistics into spare parts inventory management $[37,38]$. Another interesting problem within this topic is spare parts additive manufacturing. Unlike normal spare part manufacturing 
process, additive manufacturing is able to produce the parts with complex structures in a responsive manner but with a high cost. Therefore, questions regarding when to use additive manufacturing for producing spare parts and how to design an inventory system suitable for spare parts additive manufacturing are worth studying. The representative studies are $[23,26,39]$, and readers may refer to [40] for a more detailed literature review on additive manufacturing for spare parts.

\subsubsection{Spare Parts Classification and Demand Forecast}

In the reviewed literature, there are 28 studies in this category. Among them, 10 studies focus on developing various multiple-criteria classification schemes for spare parts inventory management in different industries. In addition, 18 studies focus on spare parts demand forecast, and many methods are proposed, including Croston's method, Syntetos-Boylan approximation, single exponential smoothing (SES), and bootstrapping methods. Importantly, to integrate spare parts demand forecasting and inventory management, forecasting methods should be evaluated through inventory management metrics instead of performance metrics, which are directly related to forecasting results (e.g., mean squared error) [41]. For instance, ref [42] used extreme value theory to forecast spare parts demand, and the method was evaluated by inventory performance. In addition, forecasting methods could utilize more information from maintenance activities. For instance, ref [43] combined the failure behavior of parts and the maintenance plan of equipment to predict spare parts demand.

To further reveal the developing trend in research topics, we present the histogram for each topic in chronological order in Figure 2. The figure clearly shows the studies on joint maintenance and inventory optimization dominated at the beginning of the decade for several years. Entering the year 2017, joint maintenance and inventory optimization studies started to lose their dominant status because studies on other topics, especially studies on spare parts inventory management problems, grew in popularity rapidly. This trend indicates that studies on spare parts inventory management are starting to grow as an independent research field distinct from the equipment maintenance field.

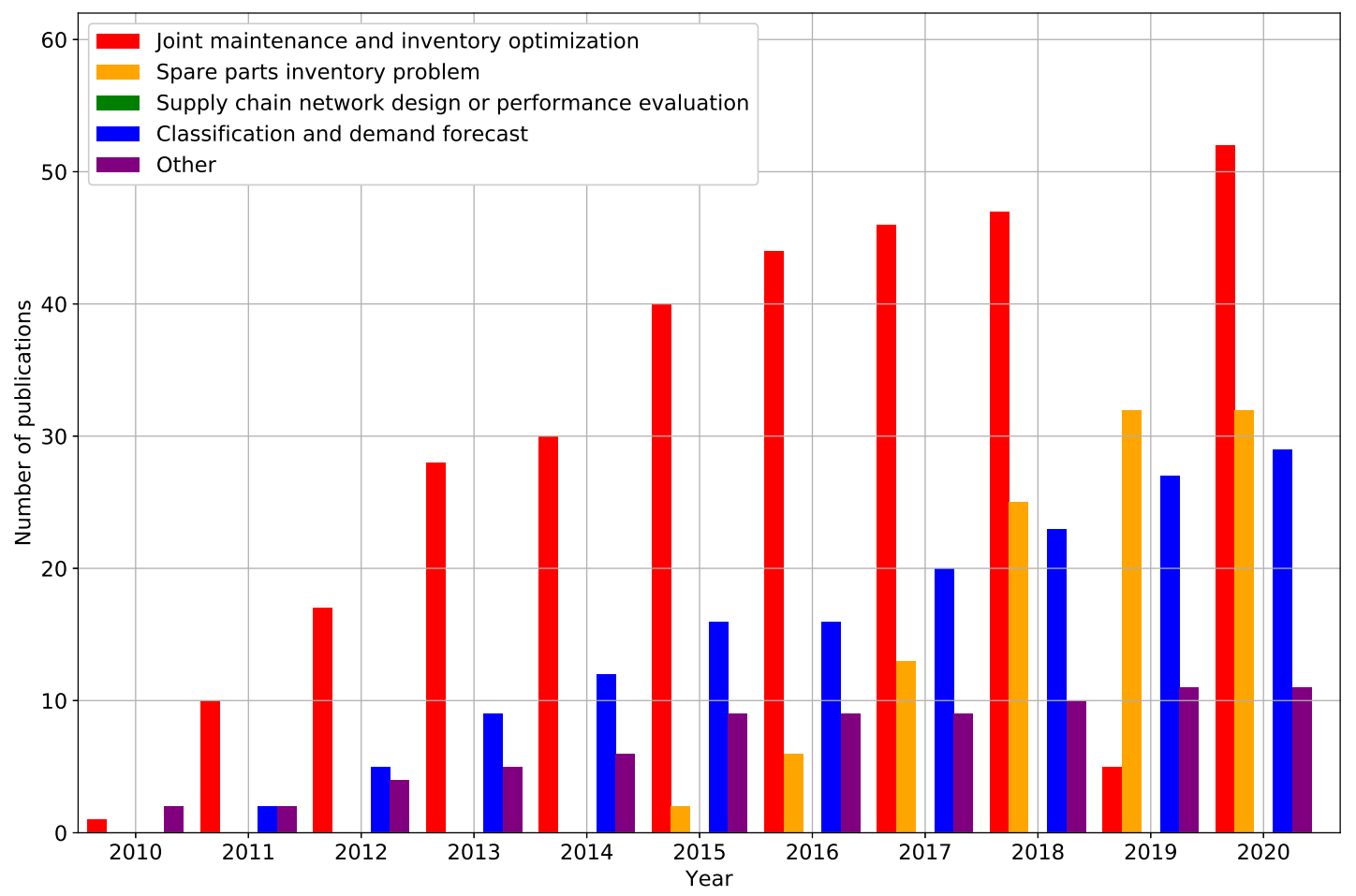

Figure 2. Cumulative number of studies with different topics. 


\section{Conclusions and Future Research}

To clearly present the developing trend of spare parts inventory management research, the reviewed studies are grouped according to the publication year. Afterwards, the number of studies in each year is aggregated and chronically illustrated in Figure 3.

From the figure, we can see that studies on spare parts inventory management have experienced steady growth in the last decade. This trend clearly indicates an increasing interest in this field. In the following section, research gaps are identified and corresponding extensions are proposed for researchers who intend to conduct further research in this area.

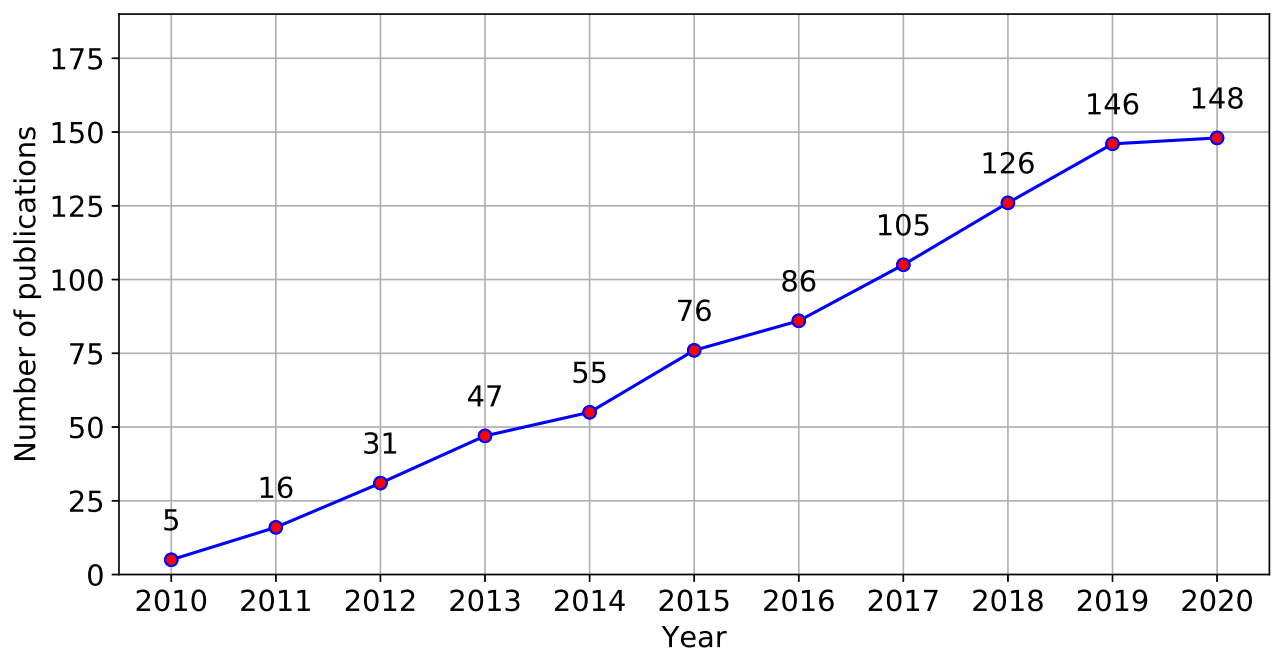

Figure 3. Cumulative number of studies in spare parts inventory management.

\subsection{Research Gaps and Extensions}

Based on the classifications made in previous sections, we identify research gaps in the following aspects, including reverse logistics, consumer durable goods, supply chain network structure and policies, spare parts demand pattern modeling, and big data analytics implementation. All the research gaps are summarized in Table 9.

\subsubsection{Research Gaps Regarding Reverse Logistics}

As environmental concerns have been increasingly growing in recent years, the concept of supply chain sustainability is widely advocated for in industry and academia. Reverse logistics (RL) is one of the most popular topics in the literature on supply chain sustainability. RL involves operations related to the return of damaged, unsold, endof-life products along with handling, consolidation, remanufacturing, and disposal [37]. To be specific, RL is the process of turning the inputs such as the used products, recycled materials, used parts into the outputs such as remanufactured products and spare parts [44]. There are four key sub-processes of RL, i.e., product acquisition, collection, inspection/sorting, and disposition [45]. Product acquisition is the first step in the RL process, referring to the acquisition of used products, components or materials from end users for further processing. After acquisition, returned items are collected in three ways: OEM collects directly from the users, OEM buys back the products collected from users by a retailer, and OEM collects products through third-party logistics [46]. The collected items are sent for inspection, sorting, and disposition. Note that disposition decisions including reuse, repair, remanufacturing, recycling, and disposal. For detailed definitions of these disposition alternatives, please refer to [45]. Spare parts inventory management has a close relationship with RL because spare parts are one of the wanted outcomes of the RL system [44]. Based on their conditions, some of these spare parts are sent back to the market as reused parts after inspection, cleaning, and minor maintenance; some are used for repairing faulty products; some are sent to remanufacture new products; and some are 
recycled as raw materials. From this perspective, it is promising to explore the integration of spare parts inventory management and RL.

Table 9. Summary of research gaps.

\begin{tabular}{|c|c|c|}
\hline Research Gaps & Current Studies & Future Studies \\
\hline Reverse logistics & $\begin{array}{l}\text { - Reverse logistics has a close rela- } \\
\text { tionship with spare parts inventory } \\
\text { management but few studies con- } \\
\text { sidering it. } \\
\text { Even though some studies incorpo- } \\
\text { rate reverse logistics in their prob- } \\
\text { lems, the considered reverse logis- } \\
\text { tics has simple settings while the } \\
\text { one in practice has more compli- } \\
\text { cated settings. }\end{array}$ & $\begin{array}{l}\text { - } \quad \text { Combine various settings in } \\
\text { structure and more inventory } \\
\text { strategies with reverse logis- } \\
\text { tics relevant to spare parts in- } \\
\text { ventory management. } \\
\text { Evaluate the performance of } \\
\text { spare parts reverse logistics } \\
\text { through a product life-cycle } \\
\text { perspective. }\end{array}$ \\
\hline $\begin{array}{l}\text { Spare parts of consumer } \\
\text { durable goods }\end{array}$ & $\begin{array}{l}\text { - } \quad \text { Few studies on the spare parts of } \\
\text { durable consumer goods. } \\
\text { - } \quad \text { Lack life-cycle planning perspective. } \\
\text { - } \quad \text { Simple warranties are considered. } \\
\text { ing strategy and spare parts inven- } \\
\text { tory management. }\end{array}$ & $\begin{array}{l}\text { - } \quad \text { Consider life-cycle planning } \\
\text { perspective } \\
\text { - Consider advanced warranty } \\
\text { types of durable consumer } \\
\text { goods. } \\
\text { - Integrate product marketing } \\
\text { strategies and spare parts in- } \\
\text { ventory management. }\end{array}$ \\
\hline $\begin{array}{l}\text { Inventory network struc- } \\
\text { ture and policies }\end{array}$ & $\begin{array}{l}\text { - Most of studies consider single- } \\
\text { echelon structure and lack of imple- } \\
\text { mentation of transshipment strate- } \\
\text { gies. }\end{array}$ & $\begin{array}{l}\text { - Investigate and evaluate lat- } \\
\text { eral or emergency transship- } \\
\text { ments in the multi-echelon } \\
\text { inventory system. }\end{array}$ \\
\hline $\begin{array}{l}\text { Spare parts demand pat- } \\
\text { tern modeling }\end{array}$ & $\begin{array}{l}\text { - Stationary stochastic process is } \\
\text { mainly used to depict spare parts } \\
\text { demand in the reviewed studies. }\end{array}$ & $\begin{array}{l}\text { - Non-stationary stochastic pro- } \\
\text { cess or general probability dis- } \\
\text { tribution should be used. }\end{array}$ \\
\hline Big data analytics & $\begin{array}{l}\text { - Few reviewed studies implement big } \\
\text { data analytics (BA). }\end{array}$ & $\begin{array}{l}\text { - Facilitating BA in demand fore- } \\
\text { casting, inventory system de- } \\
\text { sign, and system optimization. }\end{array}$ \\
\hline
\end{tabular}

Among the reviewed studies, there are several studies considering reverse logistics. Ref [37] studied an uncapacitated closed-loop location inventory model in which one type of returned products is collected and salvaged into spare parts which can be reused. Ref [15] dealt with a hybrid manufacturing/remanufacturing system for providing spare parts to support the after-sales service to the products in the EOL phase. Ref [38] considered a single-echelon reverse supply chain where the returned products are remanufactured as spare parts and then sent back to retailers. In their problem, new items are produced either from manufacturing using externally supplied materials or from remanufacturing using returned items. Ref [22] proposed heuristic inventory policies to control a manufacturing/remanufacturing system with downward product substitution. In addition, a downward substitution strategy is used, i.e., when a lower-value item stocks out, a higher-value item is substituted to meet the demand to reduce the stock-out cost. Ref [47] introduced a spare parts inventory control problem for an OEM who remanufactures spare parts from returned products to meet warranty demand under part obsolescence.

The mentioned existing studies on RL in spare parts inventory management often have simplified settings. More research on this topic can consider the extensions as follows. 
First of all, the supply chain structure in the existing studies is quite simple: only [37] considered a two-echelon inventory network, while the other studies considered single-echelon networks. Second, all these studies only focussed on one phase of product life-cycle, so the change in installed base was not considered as one impacting factor of returned products quantity. Third, various inventory strategies such as lateral and emergency transshipments were not considered even though these strategies may improve RL performance. For example, RL is common in electronics supply chains such as cell phone, personal computer, etc. In these supply chains, returned products are disposed of to remanufacture new products which can be either sold as new ones or used as replacements. Considering the worldwide retailing network an OEM may possess, how to collect the returned products from the retailers over different geographical regions, then dispose collected returns and use spare parts to remanufacture new products, and finally allocate the remanufactured products to those retailers is a relevant and challenging problem. In addition, lateral and emergency transshipments can be used to move the remanufactured products within the retailing network to decrease stock-out cases and customer waiting time. Lastly, it is necessary to study how to allocate the inventory of different spare parts which are used in different disposition alternatives. Optimal inventory policies need to be made for each type of spare part with different disposition alternatives, so that corresponding costs are lowered.

\subsubsection{Research Gaps Regarding Consumer Durable Goods}

The differences between consumer durable goods and capital goods are identified in previous contents. Based on these differences, the following research gaps are identified, and corresponding extensions are proposed.

a. Spare parts inventory problems of consumer durable goods

As mentioned in Section 2.1, most of the current literature targets managing the spare parts of capital goods. The reason for this phenomenon is two-fold. Firstly, the literature on spare parts inventory management originates from and is highly impacted by the literature on capital equipment maintenance scheduling. Capital equipment usually requires a high availability level. Therefore, spare parts inventory management plays a critical role in maintenance activities because sufficient a spare parts inventory can effectively reduce equipment downtime and improve equipment availability. Secondly, the spare parts of capital equipment are usually high-value components with a high specificity level. The inventory management on such spare parts is able to create significant performance improvements in both economic and service perspectives. However, there are very few studies focusing on the inventory problems of consumer durable goods. Unlike capital goods, consumer durable goods usually have a shorter life-cycle and a bigger consumer base. The inventory planning period of spare parts in consumer durable goods is shorter and spare parts demand is more variant. The spare parts inventory of consumer durable goods is normally held by an OEM or third-party service provider to fulfill warranty contracts, whilst that of capital goods is held to support maintenance services which are regulated by service contracts. Warranty contracts often do not have specific requirements on product performance, while service contracts do. In this sense, the spare parts inventory management of consumer durable goods is more appropriate to be operated in a cost-minimizing manner. The aforementioned differences indicate that existing inventory policies for the spare parts of capital goods are not likely to be optimal for that of consumer durable goods. New research on the spare parts of consumer durable goods should focus on the aforementioned differences and incorporate various inventory management operations into studied problems.

Based on these differences, two research gaps are identified as follows. The first research gap is that the studies on managing the spare parts inventory of consumer durable goods lack the perspective of life-cycle planning. Only one study focuses on the lifetime spare parts procurement problem for consumer durable goods [48]. Studies on consumer durable goods are more suitable to implement the perspective of life-cycle planning than those on capital goods due to the following reasons. First, consumer durable goods 
normally have shorter life-cycles and OEMs prefer rapid product development. In some industries, such as electronics and telecommunications, it is common for an OEM to finish the production processes even before the products are available in retail outlets [48]. Consequently, OEMs often cannot procure spare parts to support maintenance operations during the product warranty time after observing the demand and subsequent return rates of defective products. Second, for the same reason, OEMs launch new products quickly to keep the competitive advantages of their products, leading to multiple product generations being on the market simultaneously. When an OEM switches its production to a new generation or a new model, suppliers incur high retooling costs to produce new parts. In this case, due to the high setup cost, they are not willing to produce the parts in old generations or models in another production after the first production. Therefore, the spare parts of older products may not be available when the production of these products ceases. In this case, OEMs need to develop a specific life-cycle spare parts managing plan for each product generation.

The second research gap is how to manage the spare parts inventory of consumer durable goods under warranty contracts. There are several existing studies focusing on this topic, such as $[11,13,24,49,50]$. However, these studies have various settings, focusing on different phases in the product life-cycle and considering different types of spare parts (repairables or non-repairables), while only considering basic warranties. New studies on exploring the spare part inventory control under advance warranty contracts are needed. For example, extended warranties are provided by OEMs for certain prices as value-added services and they actually generate revenue for the OEMs. Therefore, how to manage the spare parts inventory system to support such profit-generating contracts is a critical problem to maximize the profits. In addition, for some consumer durable goods, warranty periods are usually restricted in two dimensions, such as the product age and usage [51]. A good example of two-dimensional warranty contracts is the automobile warranty. It is worth investigating how to manage a spare parts inventory to support maintenance activities under two-dimensional warranty contracts.

b. Multiple substitutable products sharing a spare parts inventory system

Nowadays, OEMs are inclined to use product segmentation strategies in which multiple substitutable models belonging to one product category are provided to customers from different groups. In the literature, such a product category containing several models is normally referred as a product assortment. One real-life example of product assortment is that one automobile manufacture sells several car models at different prices in various markets, while these models may contain similar and different parts. In this case, the sales quantity of each car model is highly governed by customer preferences regarding the assortment of cars, resulting in different market shares captured by different car models. For the spare parts which are used by different models, inventory management issues are more complicated because the demand patterns of these spare parts are hard to model. The car failure numbers are determined by two factors including the quantity of cars on market and failure rate of each car model. First, the quantity of cars on the market is different across all car models in the range. Second, in general, different car models prohibit various failure rates because of the differences in car design, manufacturing, and usage conditions. Consequently, the aggregated spare part demand should be estimated by taking the mentioned factors into consideration. The illustrated example is not limited to the automobile industry, and can be extended to other industries using product segmentation strategies.

\subsubsection{Research Gaps Regarding Inventory Network Structure and Policies}

More studies could focus on the following aspects of inventory network structure and polices: multi-echelon spare parts inventory systems and lateral and emergency transshipments. As discussed in Section 2.2, compared to the studies focusing on singleechelon inventory systems, the studies considering multi-echelon inventory systems are limited in number: There are 31 studies adopting a multi-echelon inventory setting, while 91 studies adopt a single-echelon inventory system. The multi-echelon inventory system 
for managing spare parts represents a more common scenario in practice, especially for OEMs or third-party organizations who are responsible for maintaining the products over different geographic districts. In addition, other extensions regarding inventory policy could be designed for multi-echelon structures. For example, the inventory pooling strategy could be implemented in a multi-echelon system. Lateral transshipment and emergency shipments are usually applied in a multi-echelon system. In practice, they can bring about significant performance improvement by providing timely maintenance service. However, the discussions in Section 2.2 illustrate that only 24 studies consider lateral or emergency transshipment. Therefore, more studies could incorporate lateral or emergency transshipments into their inventory systems.

\subsubsection{Research Gaps Regarding Spare Parts Demand Pattern Modeling}

From the perspective of modeling spare parts demand patterns, attention should be paid to the implementation of non-stationary stochastic processes and general probability distributions. The demand pattern of spare parts is usually intermittent and lumpy. The studies adopting predictive analytics in the reviewed literature normally target how to identify different demand patterns of spare parts and correctly forecast the spare parts demands. As discussed in Section 3.1, most studies model the demand pattern of spare parts as stationary stochastic processes such as the Poisson process by assuming that the demand pattern, as a random variable, follows a exponential probability distribution which does not change over planning periods. This assumption makes sense when the installed base of the product is in a steady-state condition and the product reliability is relatively mature [52]. In other words, the stationary stochastic process can be adopted when the studied product is in the mature phase of its life-cycle. Modeling spare parts demand patterns as a stationary stochastic processes can make the optimization model relatively simpler, thus structural results might be achieved. However, the demand pattern cannot be modeled as a stationary stochastic process when the planning horizon spans over several phases of the life-cyle or over the entire life-cycle, because the product's installed base changes over different phases. Therefore, non-stationary stochastic processes or general probability distributions should be used for modeling the demand patterns of spare parts. As shown in Table 7 in Section 3.1, there are only 10 studies using non-stationary stochastic processes and 20 studies using general probability distributions to capture the demand pattern, respectively, compared to 74 papers using stationary stochastic processes. Hence, more studies are required to extend the current literature by using non-stationary stochastic processes and general probability distributions to model spare part demand patterns.

\subsubsection{Research Gaps Regarding Implementing Big Data Analytics}

Big data analytics (BA) is the study of practices, technologies and skills to evaluate operations and strategies to obtain insights and offer guidance to the business planning of an organization [53]. Such evaluation is done for product development, strategic management, and customer services by utilizing evidence-based data, statistical and operations analysis, predictive modeling, forecasting, and optimization techniques [54]. There is a clear gap in the reviewed literature in that BA is barely used, and this research area can be further enriched by implementing BA in several interesting aspects including demand forecasting, inventory system design, and inventory system optimization. The typical literature of spare parts inventory management mainly focuses on managing at most a hundred kinds of spare parts in the inventory, while it is common to see more than thousands of spare parts held in practice. There is only one paper proposing a smart spare parts inventory management system in a semiconductor company for obtaining more information which can be used in BA [55]. The reason behind this phenomenon is that the computation capacity is limited when a huge number of spare parts are considered in the demand forecasting or optimization processes. Therefore, classic statistics or optimization methods are not applicable when faced with a large spare parts inventory to manage. In this case, BA is 
useful when massive data are available. More research can be performed regarding how to build a smart system adopting BA to manage the spare parts inventory.

\subsection{Concluding Remarks}

In this review, 142 studies on spare parts inventory management have been surveyed and classified. Our review has the following distinct features. Firstly, it provides a quick guide to a variety of classification schemes for spare parts inventory management literature. Two different typologies are used for the literature classification. One typology classifies the literature based on systematic characteristics of spare parts inventory systems, while the other typology is based on research methodologies and topics. Importantly, we classify the research methodology from the perspective of supply chain analytics. Existing studies using descriptive, predictive, and prescriptive analytics are identified. Secondly, this review presents a big picture on spare parts supply chains to discuss the studies on spare parts inventory management. This big picture links the vital aspects related to managing a spare parts inventory, such as product and spare part types, after-sales services, maintenance operations, inventory management strategies and policies, supply sources, and demand patterns, etc. Finally, research gaps and extensions are discussed. Among the discussed gaps, we emphasize combining spare parts inventory management with reverse logistics. This gap is worth exploring, since more and more manufacturers are starting to collect the used products from customers for the purpose of reusing or remanufacturing.

The studies in this research field have been experiencing steady growth in the last decade. Researchers have put plenty of effort into the study of spare parts of capital goods. We expect to see more studies on managing the spare parts of durable consumer goods. Moreover, new supply chain concepts such as reverse logistics and supply chain analytics bring new avenues to this field, but have to be tested and evaluated through more studies. One promising area for future research could be the study which combines the supply chain inventory management problem with big data analytics. Big data analytics could contribute to many aspects such as spare parts demand forecasting, spare parts inventory system optimization, and spare parts classification, when a large number of spare parts need to be managed. The second area will be how to integrate spare parts inventory management with supply chain sustainability concepts such as additive manufacturing and the circular economy.

Author Contributions: Conceptualization, S.Z.; Supervision, K.H. and Y.Y.; Writing—original draft, S.Z.; Writing-review \& editing, K.H. All authors have read and agreed to the published version of the manuscript.

Funding: This research received no external funding.

Institutional Review Board Statement: Not applicable.

Informed Consent Statement: Not applicable.

Data Availability Statement: Not applicable.

Conflicts of Interest: The authors declare no conflict of interest.

\section{References}

1. Apple Inc. iPhone 12 Product Environmental Reports. Available online: http://www.apple.com/environment/ (accessed on 14 December 2020).

2. Rosa-Quino, P. Fix, or Toss? The 'Right to Repair' Movement Gains Ground. New York Times, 24 October 2020, Section B, p. 3.

3. Kennedy, W.J.; Patterson, J.W.; Fredendall, L.D. An overview of recent literature on spare parts inventories. Int. J. Prod. Econ. 2002, 76, 201-215. [CrossRef]

4. $\mathrm{Hu}, \mathrm{Q} . ;$ Chakhar, S.; Siraj, S.; Labib, A. Spare parts classification in industrial manufacturing using the dominance-based rough set approach. Eur. J. Oper. Res. 2017, 262, 1136-1163. [CrossRef]

5. Jin, T.; Tian, Y. Optimizing reliability and service parts logistics for a time-varying installed base. Eur. J. Oper. Res. 2012, 218, 152-162. [CrossRef]

6. Cho, D.I.; Parlar, M. A survey of maintenance models for multi-unit systems. Eur. J. Oper. Res. 1991, 51, 1-23. [CrossRef]

7. Guide, V.D.R.; Srivastava, R. Repairable inventory theory: Models and applications. Eur. J. Oper. Res. 1997, 102, 1-20. [CrossRef] 
8. Paterson, C.; Kiesmüller, G.; Teunter, R.; Glazebrook, K. Inventory models with lateral transshipments: A review. Eur. J. Oper. Res. 2011, 210, 125-136. [CrossRef]

9. Van Horenbeek, A.; Buré, J.; Cattrysse, D.; Pintelon, L.; Vansteenwegen, P. Joint maintenance and inventory optimization systems: A review. Int. J. Prod. Econ. 2013, 143, 499-508. [CrossRef]

10. Basten, R.J.I.; van Houtum, G. System-oriented inventory models for spare parts. Surv. Oper. Res. Manag. Sci. 2014, 19, 34-35. [CrossRef]

11. Rezapour, S.; Allen, J.K.; Mistree, F. Reliable flow in forward and after-sales supply chains considering propagated uncertainty. Transp. Res. Part E Logist. Transp. Rev. 2016, 93, 409-436. [CrossRef]

12. Arts, J.J. Spare parts planning and control for maintenance operations. In Proceedings of the Second International Conference on Railway Technology: Research, Development and Maintenance, Ajaccio, France, 8-11 April 2014.

13. Pourakbar, M.; Frenk, J.B.G.; Dekker, R. End-of-life inventory decisions for consumer electronics service parts. Prod. Oper. Manag. 2012, 21, 889-906. [CrossRef]

14. Solomon, R.; Sandborn, P.; Pecht, M.G. Electronic part life cycle concepts and obsolescence forecasting. IEEE Trans. Components Packag. Technol. 2000, 23, 707-717.

15. Inderfurth, K.; Mukherjee, K. Decision support for spare parts acquisition in post product life cycle. Cent. Eur. J. Oper. Res. 2008, 16, 17-42. [CrossRef]

16. Moharana, U.C.; Sarmah, S.P. Determination of optimal order-up to level quantities for dependent spare parts using data mining. Comput. Ind. Eng. 2016, 95, 27-40. [CrossRef]

17. Liu, X.; Tang, L.C. Reliability analysis and spares provisioning for repairable systems with dependent failure processes and a time-varying installed base. IIE Trans. 2016, 48, 43-56. [CrossRef]

18. Asiedu, Y.; Gu, P. Product life cycle cost analysis: State of the art review. Int. J. Prod. Res. 1998, 36, 883-908. [CrossRef]

19. Öner, K.B.; Kiesmüller, G.P.; van Houtum, G.J. Optimization of component reliability in the design phase of capital goods. Eur. J. Oper. Res. 2010, 205, 615-624. [CrossRef]

20. Ellram, L.M. Total cost of ownership: An analysis approach for purchasing. Int. J. Phys. Distrib. Logist. Manag. 1995, 25, 4-23. [CrossRef]

21. Pfohl, H.C.; Ester, B. Benchmarking for spare parts logistics. Benchmarking Int. J. 1999, 6, 22-45. [CrossRef]

22. Ahiska, S.S.; Gocer, F.; King, R.E. Heuristic inventory policies for a hybrid manufacturing/remanufacturing system with product substitution. Comput. Ind. Eng. 2017, 114, 206-222. [CrossRef]

23. Zhao, Q.; Chang, R.; Ma, J.; Wu, C. System dynamics simulation-based model for coordination of a three-level spare parts supply chain. Int. Trans. Oper. Res. 2019, 26, 2152-2178. [CrossRef]

24. Li, Y.; Zhao, Q.; He, S. Determination of the warranty service method switch time of old generation products after new generation products launched. Int. J. Qual. Reliab. Manag. 2018, 35, 291-311. [CrossRef]

25. Topan, E.; Bayındır, Z.P.; Tan, T. Heuristics for multi-item two-echelon spare parts inventory control subject to aggregate and individual service measures. Eur. J. Oper. Res. 2017, 251, 126-138. [CrossRef]

26. Togwe, T.; Eveleigh, T.J.; Tanju, B. An additive manufacturing spare parts inventory model for an aviation use case. Eng. Manag. J. 2019, 31, 69-80. [CrossRef]

27. Song, Y.; Yang, J. Simulation of dynamics behaviors for shipping equipment support with system dynamics analysis approach J. Ind. Eng. Manag. 2015, 8, 636-657. [CrossRef]

28. Dreyfuss, M.; Giat, Y. Optimal spares allocation to an exchangeable-item repair system with tolerable wait. Eur. J. Oper. Res. 2017, 261, 584-594. [CrossRef]

29. Wong, H.; van Houtum, G.J.; Cattrysse, D.; Van Oudheusden, D. Multi-item spare parts systems with lateral transshipments and waiting time constraints. Eur. J. Oper. Res. 2006, 171, 1071-1093. [CrossRef]

30. Martinez, V.; Radnor, Z.; Cavalieri, S.; Gaiardelli, P.; Ierace, S. Aligning strategic profiles with operational metrics in after-sales service. Int. J. Product. Perform. Manag. 2007, 56, 436-455.

31. Mirzahosseinian, H.; Piplani, R.; Jin, T. The impact of fleet size on performance-based incentive management. J. Oper. Res. Soc. 2016, 67, 165-175. [CrossRef]

32. Souza, G.C. Supply chain analytics. Bus. Horizons 2014, 57, 595-605. [CrossRef]

33. Boylan, J.E.; Syntetos, A.A. Spare parts management: A review of forecasting research and extensions. IMA J. Manag. Math. 2010, 21, 227-237. [CrossRef]

34. Arts, J. A multi-item approach to repairable stocking and expediting in a fluctuating demand environment. Eur. J. Oper. Res. 2017, 256, 102-115. [CrossRef]

35. Carson, Y.; Maria, A. Simulation optimization: Methods and applications. In Proceedings of the the 29th Conference on Winter Simulation, Atlanta, GA, USA, 7-10 December 1997; pp. 118-126.

36. Mo, D.Y.; Tseng, M.M.; Wang, Y. Mass customizing spare parts support services based on response time with inventory pooling strategies. IEEE Trans. Eng. Manag. 2016, 63, 305-315. [CrossRef]

37. Abdallah, T.; Diabat, A.; Simchi-Levi, D. Sustainable supply chain design: A closed-loop formulation and sensitivity analysis. Prod. Plan. Control 2012, 63, 1467-1478. [CrossRef]

38. Diabat, A.; Abdallah, T.; Henschel, A. A closed-loop location-inventory problem with spare parts consideration. Comput. Oper. Res. 2015, 54, 245-256. [CrossRef] 
39. Den Boer, J.; Lambrechts, W.; Krikke, H. Additive manufacturing in military and humanitarian missions: Advantages and challenges in the spare parts supply chain. J. Clean. Prod. 2020, 257, 120301. [CrossRef]

40. Frandsen, C.S.; Nielsen, M.M.; Chaudhuri, A.; Jayaram, J.; Govindan, K. In search for classification and selection of spare parts suitable for additive manufacturing: A literature review. Int. J. Prod. Res. 2020, 58, 970-996. [CrossRef]

41. Van Wingerden, E.; Tan, T.; Van Houtum, G.J. The impact of an emergency warehouse in a two-echelon spare parts network. Eur. J. Oper. Res. 2019, 276, 983-997. [CrossRef]

42. Zhu, S.; Tan, T.; Dekker, R.; Van Jaarsveld, W.; Wang, R.; Koning, A.J. An improved method for forecasting spare parts demand using extreme value theory. Eur. J. Oper. Res. 2017, 261, 169-181. [CrossRef]

43. Van der Auweraer, S.; Boute, R. Forecasting spare part demand using service maintenance information. Int. J. Prod. Econ. 2019, 213, 138-149. [CrossRef]

44. Pokharel, S.; Mutha, A. Perspectives in reverse logistics: A review. Resour. Conserv. Recycl. 2009, 53, 175-182. [CrossRef]

45. Agrawal, S.; Singh, R.K.; Murtaza, Q. A literature review and perspectives in reverse logistics. Resour. Conserv. Recycl. 2015, 97, 76-92. [CrossRef]

46. Kumar, S.; Putnam, V. Cradle to cradle: Reverse logistics strategies and opportunities across three industry sectors. Int. J. Prod. Econ. 2008, 115, 305-315. [CrossRef]

47. Shi, Z. Optimal remanufacturing and acquisition decisions in warranty service considering part obsolescence. Comput. Ind. Eng. 2019, 135, 766-779. [CrossRef]

48. Sahyouni, K.; Savaskan, R.; Daskin, M.S. The effect of lifetime buys on warranty repair operations. J. Oper. Res. Soc. 2010, 61, 790-803. [CrossRef]

49. Frenk, J.B.G.; Javadi, S.; Pourakbar, M.; Sezer, S.O. An exact static solution approach for the service parts end-of-life inventory problem. Eur. J. Oper. Res. 2019, 272, 496-504. [CrossRef]

50. Frenk, J.B.G.; Javadi, S.; Pourakbar, M.; Sezer, S.O. An optimal stopping approach for the end-of-life inventory problem. Math. Methods Oper. Res. 2019, 90, 329-363. [CrossRef]

51. Shafiee, M.; Chukova, S. Maintenance models in warranty: A literature review. Eur. J. Oper. Res. 2013, 229, 561-572. [CrossRef]

52. Jin, T.; Taboada, H.; Espiritu, J.; Liao, H. Allocation of reliability-redundancy and spares inventory under Poisson fleet expansion. IISE Trans. 2017, 49, 737-751. [CrossRef]

53. Wang, G.; Gunasekaran, A.; Ngai, E.W.T.; Papadopoulos, T. Big data analytics in logistics and supply chain management: Certain investigations for research and applications. Int. J. Prod. Econ. 2016, 176, 98-110. [CrossRef]

54. Chen, H.; Chiang, R.H.L.; Storey, V.C. Business intelligence and analytics: From big data to big impact. MIS Q. 2012, 36, 1165-1188. [CrossRef]

55. Zheng, M.; Wu, K.; Storey, V.C. Smart spare parts management systems in semiconductor manufacturing. Ind. Manag. Data Syst. 2017, 117, 754-763. [CrossRef] 